\title{
SCALE-DEPENDENT FLOW DIRECTIONS OF RIVERS AND THE IMPORTANCE OF SUB-PLATE SUPPORT
}

\author{
ACCEPTED, PEER-REVIEWED MANUSCRIPT, COMPILED DECEMBER 14, 2020
}

\author{
Alex G. Lipp ${ }^{1}$ and Gareth G. Roberts ${ }^{1}$ \\ ${ }^{1}$ Department of Earth Sciences and Engineering, Imperial College London, UK
}

\begin{abstract}
Large rivers play crucial roles in determining locations of civilization, biodiversity and efflux to the oceans. The paths they take across Earth's surface vary with scale. At long-wavelengths rivers can have simple flow paths. At smaller scales, in meanders for example, their paths change rapidly as a consequence of lithology, biota and other environmental variables. It is not straightforward to identify the scales at which river planforms are set. We overcome these issues by developing a spectral (wavelet) methodology to map flow-directions as a function of distance and scale. This methodology allows short-wavelength features (e.g. meanders) to be filtered from river flow-paths. With short-wavelength structure removed, the flow-directions of rivers in Western USA correlate with long-wavelength gravity anomalies suggesting control by sub-plate support. This relationship is replicated by an ensemble of landscape evolution models. These results combined suggest that drainage at large scales, $\mathrm{O}\left(10^{3}\right) \mathrm{km}$ is set by sub-plate support.
\end{abstract}

\section{Plain Language Summary}

Rivers play important roles in developing civilization, biodiversity and the supply of sediment and nutrients to the oceans. Their position on Earth's surface depends on geologic, climatic, hydraulic and biologic processes, which operate at a large range of spatial and temporal scales. Rivers obviously flow from high to low topography, however their paths vary at a range of scales. They can be determined by, for example, rock fractures, biota and antecedence (pre-existing drainage patterns). It is generally unclear what processes determine the flow directions of rivers across the scales of interest. Here, a methodology is developed to map the scale-dependent shapes of rivers, which can be compared to independent observations at appropriate scales. This spectral approach is used to quantify how rivers' flow directions change as a function of scale. We show that it can be used to remove small-scale variations in flow directions (e.g. meanders) leaving only the larger-scale changes in flow direction of western North American rivers. The flow direction of these rivers at large scales run broadly parallel to the line-of-descent of Earth's gravity field and away from areas where the lithosphere is thin. This result is consistent with western North American drainage patterns being principally controlled by mantle convection.

\section{INTRODUCTION}

Despite its general importance, the way in which drainage networks acquire their planforms is poorly understood across different length scales. Evolution of the solid Earth (orogenesis, crustal thickening and mantle convection) is an obvious means to determine flow paths by generating extensive areas of elevated terrain (e.g. Cox 1989). Lithologic and internal hydraulic processes can also generate complex paths such as meanders (Scheingross et al. 2020). Drainage planforms can also be determined by antecedence (pre-existing flow directions) resulting in hysteresis behaviour and they can be modified by drainage capture/piracy (e.g. Shugar et al. 2017). Anthropic and biotic processes are also important means by which drainage networks can be generated and modified (Rinaldo et al. 1993; Anderson and Anderson 2010). The processes controlling drainage planforms are, to some degree, scale dependent. For example, fluvial hydraulics can generate meanders at scales $<10 \mathrm{~km}$. This process is independent of vertical lithospheric motion which can determine the paths of rivers at scales $>1000 \mathrm{~km}$. In this contribution we are concerned with separating the flow directions of rivers into constituent scales and identifying where the dominant signals are generated. It provides a basis for comparing flow directions to independent (e.g. geologic) observations at appropriate scales.

Whilst it may seem trivial that rivers flow down topographic gradients, they can follow circuitous routes at a range of scales. At short $(<100 \mathrm{~km})$ length scales flow-directions can be extremely variable, which can result in rivers flowing in the opposite direction to the long wavelength topographic gradient (e.g. Goosenecks, San Juan River, USA). These simple observations indicate that river planforms are scale dependent.

In many instances visual inspection of drainage planforms provides most of the information we need. For example, the Colorado River, which drains western North America, flows mostly to the west, southwest and south in its upper, mid- and lower reaches, respectively (Figure 1). The planform of rivers on top of topographic swells in other continents also have similarly simple patterns at long, $\mathrm{O}\left(10^{3}-10^{4}\right) \mathrm{km}$, wavelengths (Rudge et al. 2015). At these long wavelengths rivers mostly flow away from crests of topographic swells that are supported by the mantle (Roberts et al. 2012; Braun et al. 2013; Faccenna et al. 2019). This pattern of emergent simplicity at long wavelengths is manifest in the flow paths of many large rivers draining topographic swells and tectonic topography on Earth, e.g. African swells, Colorado Plateau, Mexican Highlands, East Australian High- 


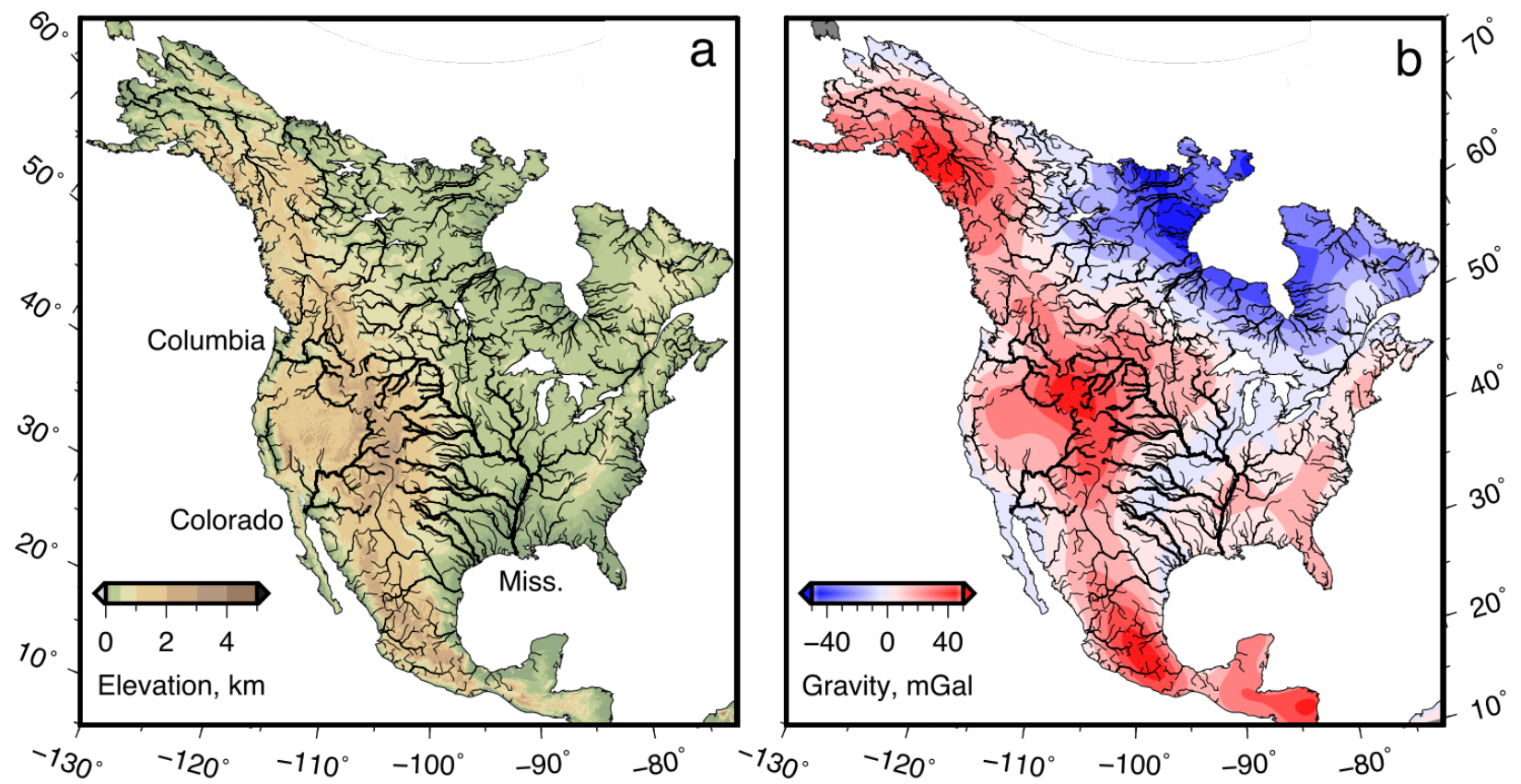

Figure 1: North American drainage overlain on topography and long wavelength free-air gravity. (a) Selected North American drainage networks extracted from ASTER DEM overlain on ETOPO1 DEM. Major rivers in this study are shown by thick black annotated curves; Miss = Mississippi. (b) Drainage overlain on long wavelength $(>800 \mathrm{~km})$ GRACE free-air gravity anomalies; contour interval $=10 \mathrm{mGal}$ (Tapley et al. 2005). If admittance $Z \sim 25 \mathrm{mGal} / \mathrm{km}$, calculated dynamic support of western North America is up to $\sim 1.5 \mathrm{~km}$. Note broadly radial drainage patterns that flow away from crests of positive dynamic topography (red contours).

lands, Himalayas, and elsewhere, e.g. Tharsis Rise, Mars (Black et al. 2017). These diverse examples suggest that the sub-plate mantle plays an important role in setting drainage planforms (e.g. Braun 2010).

This contribution has two primary goals. First, we seek to formalise the observations of scale-dependency by developing a spectral methodology to map planforms and flow directions as a function of scale and position. We explore one way in which this approach can be used to compare drainage patterns to environmental variables at appropriate scales. Secondly, we explore how planforms can be predicted a priori given forcing by sub-plate support. We achieve this second goal using an ensemble of landscape evolution models.

\section{WaVelet Analysis}

A number of approaches could be used to analyze the variability of flow-directions at different scales. Fractal approaches have been used to investigate scales of self-similarity in river planforms (Rinaldo et al. 1993). Simple filtering (e.g. box-car, Gaussian) could also be applied. A spherical harmonic approach has been used to compare flow directions of rivers to long wavelength topography (Black et al. 2017). Spectral approaches have a number of benefits including mapping of spectral power (e.g. red, pink or white noise), which can be diagnostic of scaling regimes and specific processes. We avoid using standard Fourier transforms because flow directions are not necessarily periodic (i.e. they are non-stationary signals). Instead we make use of continuous wavelet transforms (Daubechies 1990; Farge 1992; Kumar and Foufoula-Georgiou 1997; Torrence and
Compo 1998). There is a precedent for transforming directional time series into the frequency and frequency-distance domains in the atmospheric and oceanic sciences (Donelan et al. 1985, 1996). Wavelet analysis has previously been applied to the curvature of river meanders (e.g. Gerven and Hoitink 2010; Gutierrez and Abad 2014) but not to the flow-direction.

Recent wavelet spectral analyses of longitudinal river profiles, i.e. elevation as a function of distance, $z(x)$, has shown that the shape of large African rivers is mostly determined at wavelengths $>100 \mathrm{~km}$ where their power spectra, $\phi(k)$, can be characterised as red noise, i.e. $\phi \propto k^{-2}$, where $k$ is wavenumber (Roberts et al. 2019). At shorter wavelengths power appears to have a pink noise spectrum, $\phi \propto k^{-1}$. These observations give a basis for modelling longitudinal river profiles as systems that possess self-similar scaling and deterministic behaviour at long wavelengths that emerges despite local complexity. It gives a basis for understanding why at large length scales, $\mathrm{O}\left(10^{2}-10^{3}\right)$ $\mathrm{km}$, river profiles on top of dynamically supported topography (e.g. Bié dome, West Africa) have common shapes (Roberts 2019). In this study, we develop wavelet spectral techniques to map flow directions of continental-scale drainage patterns as a function of distance and wavelength.

\subsection{Data and Methods}

This section contains, first, a description of data used to extract drainage patterns and second, methodologies to perform wavelet transformations of a series of directions. Software to perform directional wavelet analysis is provided (github.com/ alexlipp/directional-wavelets). 

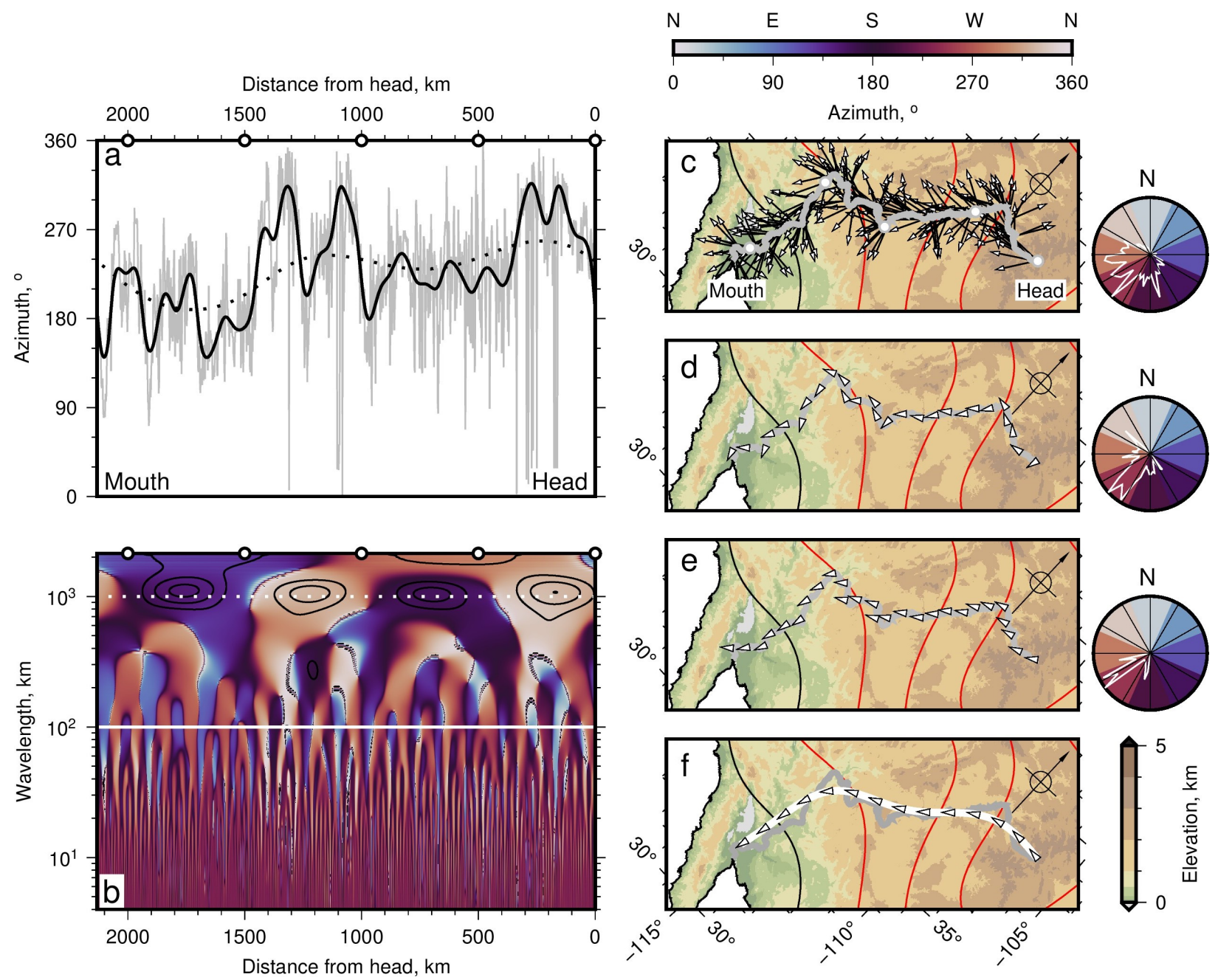

Figure 2: Deconvolution of flow directions: Example from Colorado River. (a) Gray curve $=$ calculated azimuths of Colorado River $(\delta x=2 \mathrm{~km})$. Solid and dotted black curves = azimuths filtered to remove wavelengths $\lambda<100 \mathrm{~km}$ and $<1000 \mathrm{~km}$, respectively. Note that distance is from river head and azimuths are measured in downstream direction. (b) Azimuths as function of distance and wavelength. Colours are centred on cardinals and intercardinals; light blue/dark blue/purple/orange = north/east/south/west; see scale bar and rose diagrams aside panels c-e. Solid and dotted white lines $=1000 \mathrm{~km}$ and $100 \mathrm{~km}$ wavelengths, respectively. Black contours $=$ regions with highest power. White circles atop panel $=$ positions along river (see panel c). (c) Colorado River (gray) and flow directions (azimuths) of full resolution dataset ( $\delta x=2 \mathrm{~km}$ ); directions are shown every $\sim 10 \mathrm{~km}$ for clarity. White circles $=$ distances shown on top of panels (a) and (b). Colours/contours $=$ topography/long wavelength $(>800 \mathrm{~km}$ ) free-air gravity anomalies, contour interval $=10 \mathrm{mGal}$, red/black contours $=$ positive/zero values (Figure $1 \mathrm{~b})$. Inset compass rose points north. Rose diagram aside shows azimuths of full resolution dataset $(\delta x=2 \mathrm{~km})$ in $5^{\circ}$ bins (white polygon); rose sectors are coloured by azimuth (see panel b). (d) \& (e) White vectors = azimuths calculated using wavelengths $\lambda>$ $100 \mathrm{~km}$ and $>1000 \mathrm{~km}$, respectively. Gray $=$ Colorado River. Rose diagrams aside show calculated azimuths for filtered datasets in $5^{\circ}$ bins. (f) White curve $=$ river planform from geodetic transform of long wavelength azimuths. Vectors $=$ long wavelength $(>$ $1000 \mathrm{~km}$ ) flow azimuths shown every $\sim 150 \mathrm{~km}$ for clarity. 
Transforming a series of directions (in the form of an azimuth between 0 and $360^{\circ}$ ) has several simple steps. First, the drainage dataset is extracted from the ASTER GDEM, which has a horizontal resolution of $\sim 30 \mathrm{~m}$, using Esri's D8 (steepest descent) flow routing algorithms. Second, latitudes and longitudes are resampled along flow paths (e.g. rivers) so that they have equidistant spacing, which makes them straightforward to transform into the spectral domain. In the examples used in this paper $\delta x=2 \mathrm{~km}$. Third, distances and azimuths are calculated along the path. Local (point-to-point) azimuths, $\theta(x)$, are extracted using the gmt mapproject algorithm (Wessel et al. 2013). Note that input is expected to be positions along a river with longitudes and latitudes in decimal degrees and resolution of up to a few tens of meters.

Applying wavelet transforms to a series of azimuths is challenging because the functions are discontinuous - at least one pole contains a discontinuity, e.g. $\sin \left(360^{\circ}\right)=\sin \left(0^{\circ}\right)$. To avoid this issue we represent the azimuthal series in complex form, $a(x)$. Azimuths can be considered as complex numbers of unit magnitude and variable phase, $\theta$. Making use of Euler's formula any azimuth, $\theta$, can be represented as $\exp (i \theta)$ with real part $\cos (\theta)$ and imaginary part $\sin (\theta)$, which correspond to northings and eastings, respectively. The complex series to be wavelet transformed is

$$
a(x)=\exp \left[\frac{i \theta \pi}{180}\right],
$$

where $\theta$ varies between $0^{\circ}$ and $360^{\circ}$. The azimuth series was normalised to zero mean, e.g. $a^{\prime}(x)=a(x)-\bar{a}$, prior to transformation. The resultant series of complex numbers was transformed to generate

$$
W_{x}^{a^{\prime}}(s)=\sum_{a^{\prime}=0}^{N-1} a^{\prime}(x) \psi\left[\frac{x^{\prime}-x}{s}\right] .
$$

where $\psi$ is the mother wavelet function as a function of scale, $s$. This function is the wavelet which is multiplied with the complex azimuthal series at different scales to generate the transformed series. $\psi$ is an oscillation of finite duration with maximum unit magnitude and zero mean. In the examples shown in this paper the mother wavelet is a $6^{\text {th }}$ order derivative of a Gaussian (DOG), with $\delta_{j}=0.1$, although we recognise other mother wavelets could also be used (see Torrence and Compo 1998). The chosen mother wavelet is scaled by $s$ and translated along the series by $x^{\prime}$ for $N$ data points. $W_{x}^{a^{\prime}}(s)$ is the transformed version of the complex azimuth series as a function of scale, $s$ Power of the complex series is $\left|W_{x}^{a^{\prime}}+\bar{a}\right|^{2}$. Scales are converted to Fourier periods (Torrence and Compo 1998).

Real valued azimuths (in degrees) as a function of distance and wavenumber can then be calculated as $\theta(x, k)=\zeta 180 / \pi \bmod$ 360 , where mod is the modulus operator, and $\zeta$ is the argument of the transformed (complex) series (Equation 2). $\zeta$ is computed as

$$
\zeta=\tan ^{-1}\left[\frac{\mathfrak{J}\left\{W_{x}^{a^{\prime}}(\theta, k)+\bar{a}\right\}}{\mathfrak{R}\left\{W_{x}^{a^{\prime}}(\theta, k)+\bar{a}\right\}}\right] .
$$

Note that the mean of the complex series, $\bar{a}$, is added to the reconstructed complex series in this step. The inverse wavelet transformation is simply the sum of the signal in distance-wavenumber space over scales, $j=0,1, \ldots J$. The inverse transformation of the complex series is

$$
a_{x}=\bar{a}+\frac{\delta_{j} \delta t^{1 / 2}}{1.7379} \sum_{j=0}^{J} \frac{W_{x}^{a^{\prime}}\left(s_{j}\right)}{s_{j}^{1 / 2}},
$$

for the DOG mother wavelet used in this study (Torrence and Compo 1998). Note that the subscript $x$ denotes a transformed series. The denominator factor (here 1.7379) depends on the mother wavelet used in the transformation. Real valued azimuths (in degrees) can be generated from $a_{x}$

$$
\theta_{x}=\tan ^{-1}\left[\frac{\mathfrak{I}\left\{a_{x}\right\}}{\mathfrak{R}\left\{a_{x}\right\}}\right] \frac{180}{\pi} \bmod 360 .
$$

Filtered azimuth series can now be generated by solving Equations (4) and (5) between the scales of interest. Filtered river planforms can be estimated from these azimuths by forward geodetic transformation, which returns longitudes and latitudes given a starting position (e.g. the head of the river), azimuths and distances. In this case, distances are scaled so that the final calculated position coincides with the actual river mouth. The WGS84 datum was used to perform the transformation. Whilst we consider only river paths in this study, it is straightforward to generalise this approach to other sequential paths or directional data (e.g. a time series of flow velocities and directions).

An alternative more intuitive methodology is to transform eastings and northings generated from the azimuthal series as presented in the Supporting Information. As expected, this approach gives the same results as transforming the complex form of the signal (Figure S1; Supporting Information).

There are two main sources of uncertainty in the wavelet transformation described above. First, there is uncertainty in the position of mapped river planforms. Our approach is limited to scales greater than the spatial resolution of digital elevation data (tens of meters). The fidelity of mapped rivers was assessed by comparison with independent satellite imagery. At the scales of interest (i.e. $>2 \mathrm{~km}$ ) planforms are accurately reproduced away from flat topography and standing water (e.g. lakes). There is also an uncertainty, $\delta \theta$ associated with measuring azimuths from discrete digital elevation data, which is inversely proportional to distance between cells, $L$, such that $\sin (\delta \theta)=\delta x\left(\delta x^{2}+L^{2}\right)^{-1 / 2}$ for simple east-west Euclidean flow paths, which yields an uncertainty of $\delta \theta \sim 0.9^{\circ}$ for ASTER data $(\delta x \approx 30 \mathrm{~m})$ if $L=2$ $\mathrm{km}$. If $L=100 \mathrm{~km}, \delta \theta \sim 0.02^{\circ}$. Second, spectral leakage can generate uncertainties in calculated azimuths. A guide to the fidelity of the wavelet transform is the accuracy of reconstituted series (i.e. generated by inverse transformation), which, for the examples in this paper, match the $\theta(x)$ series within a few percent in terms of error of the mean (see Supplementary Figure $\mathrm{S} 1 \mathrm{a})$. Our approach is spatially limited to the resolution of the DEM we use ( $\sim 30 \mathrm{~m}$ in this study). Additionally, we assume that channels can be represented as a single one-dimensional channel. For our DEM resolution this is a reasonable assumption excepting very large channels. Finally, we note that whilst this work is focused on single-threaded channels, the methodology could be modified to include anastomosing and braided rivers. 


\subsection{Results}

We demonstrate our approach by first transforming flow directions of the Colorado River, before analysing the wider drainage of the Western USA. The Colorado River flows across the Colorado Plateau, through the Grand Canyon, to the Gulf of California (Figure 1). Figure 2 shows the results of transforming the flow direction of the Colorado River into distance-wavenumber space. Figure 2 a shows measured azimuths from an evenly resampled $(\delta x=2 \mathrm{~km})$ dataset alongside the filtered series for wavelengths $>100 \mathrm{~km}$ and $>1000 \mathrm{~km}$. Figure $2 \mathrm{~b}$ shows Colorado River azimuths as a function of distance and wavelength $(1 / k)$. In Figure $2 c$ the azimuths for the full resolution dataset are shown as vectors with the observed river superimposed on top. These vectors are spread broadly uniformly between $150^{\circ} \leq \theta \leq 300^{\circ}$ (see rose diagram in Figure $2 \mathrm{c}$ ). Note that the map has been rotated. The filtered $>100 \mathrm{~km}$ and $>1000$ $\mathrm{km}$ azimuths and their associated rose diagrams are shown in Figures $2 \mathrm{~d}$ and $2 \mathrm{e}$. These long wavelength flow directions have, as expected, a smaller spread than the full dataset. The long wavelength azimuthal series $(\lambda>1000 \mathrm{~km})$ quantifies flow paths mapped by eye in the introductory section, i.e. flow to west $\left(\sim 270^{\circ}\right)$, southwest $\left(\sim 240^{\circ}\right)$ and south $\left(\sim 190^{\circ}\right)$ in the upper, mid and lower reaches of the river, respectively (Figure $2 \mathrm{f})$.

The white curve in Figure $2 \mathrm{f}$ shows a pseudo-Colorado River path generated using only azimuths at wavelengths $>1000$ $\mathrm{km}$ and forward geodetic transformation. This calculated flow path reinforces our assertion that most of the long wavelength structure of the Colorado River is set by just two changes in flow direction. Long wavelength flow directions of the other rivers in this study (e.g. Columbia, Mississippi) are overlain on topography and long wavelength free-air gravity anomalies in Figure $3 \mathrm{a}-\mathrm{b}$.

\subsection{Influence of sub-plate support}

Gravity anomalies, tomographic models, magmatism and isostatic calculations, which include crustal thickness estimates, indicate that western North American topography is principally a consequence of sub-crustal support moderated by tectonic and erosional processes (Atwater 1970; Wernicke 1985; Fernandes et al. 2019). A guide to the amplitude and wavelength of subplate support is the transfer function (admittance) between long wavelength free-air gravity and topography (McKenzie 2010) We note that gravity anomalies at spherical harmonic degrees appropriate for this study, $\mathrm{O}(1000) \mathrm{km}$, are particularly sensitive to upper mantle structure (Colli et al. 2016). In western North America the calculated admittance is $\sim 25 \pm 3 \mathrm{mGal} / \mathrm{km}$ at wavelengths $>1000 \mathrm{~km}$, which implies that up to $\sim 1.5 \mathrm{~km}$ of western North American topography is supported by the mantle (Stephenson et al. 2014). Figure 1b shows long wavelength free-air gravity from the GRACE dataset filtered to extract wavelengths between $\sim 800-2500 \mathrm{~km}$ (Tapley et al. 2005).

By removing the short wavelength $(<1000 \mathrm{~km})$ contributions to flow directions, we can now compare the planform of rivers draining western North America to putative evidence for subplate support at appropriate scales (Figure 3). The black vectors in Figure 3c-e show mean flow directions of the first $500 \mathrm{~km}$ of major rivers draining the Colorado-Rocky-Mountains plateaux filtered to remove wavelengths $<1000 \mathrm{~km}$. In all cases flow is directed away from the the crest of topography centred on Yellowstone and the Rio Grande rift. Figure 3c shows, for the same region, shear-wave velocity at $75 \mathrm{~km}$ depth from a recent tomographic model that incorporates data from the USArray experiment (Shen and Ritzwoller 2016). Lithospheric thicknesses generated by converting a global shear wave tomographic model into temperature using an empirical parameterisation are shown in Figure 3d (Ho et al. 2016). Cenozoic magmatism from the NAVDAT database and surficial geology from the GMNA repository are shown in Figure $3 \mathrm{e}$. There is no obvious correlation between most long wavelength azimuths and crustal thicknesses (see Supplementary Figure S2) or surficial geology (Buehler and Shearer 2017). An exception is that westernmost Cenozoic magmatism tends to be concentrated atop the crest of the swell above warm asthenosphere (e.g. Figure 3e; Figure S2; Klocking et al. 2018). All of the analysed drainage networks show long wavelength flow directed away from regions of low shear-wave velocity, positive gravity anomalies, and embayments of thin lithosphere. These observations, combined with admittance between gravity and topography, are strongly suggestive of topography and drainage patterns maintained by mantle convection.

We investigate the role the mantle plays in maintaining flow directions by comparing flows paths to gravity data (Figure 4). We start by assuming that long wavelength free-air gravity anomalies are a proxy for sub-plate support. Under the hypothesis of mantle supported topography, the long-wavelength flow-direction of rivers should flow parallel to the line of steepest gravity descent. The direction of steepest descent is calculated from the first derivative of the gravity field, $\arctan 2\left(g_{x}^{\prime}, g_{y}^{\prime}\right)$, where $g_{x}^{\prime}$ and $g_{y}^{\prime}$ are the first derivatives of the gravity field in $x$ and $y$ directions (Figure $4 \mathrm{a}$ ). Figure $4 \mathrm{~b}$ shows the position of rivers generated by forward geodetic transformation of the long wavelength components of western North America's rivers. It demonstrates that the long wavelength components of large rivers draining western North America are parallel/sub-parallel to the direction of $g^{\prime}$ along most of their lengths. $>75 \%$ of the offsets between the Colorado River and $g^{\prime}$ are $<30^{\circ}$ in magnitude. Similar results are obtained for the upper $500 \mathrm{~km}$ of the other rivers shown in Figure $4 b$ (see Figure $4 c$ ). Flow directions of the Colorado River are shown with predicted flow paths from long wavelength free-air gravity in Figure $4 d$. The largest discrepancies in flow directions at long wavelengths are at the uppermost headwaters (distances $<100 \mathrm{~km}$ ), in the Grand Canyon area $(1000<$ distance $<1500 \mathrm{~km})$ and where the Colorado River meets the Gulf of California. We suggest that these results indicate the importance of sub-plate support in setting the planform of large rivers draining western North America.

\section{SyNTHETIC AND PROBABILISTIC LANDSCAPES}

A implication of this relationship is that planforms could be predicted using proxies for sub-plate support, i.e. long-wavelength gravity anomalies. However, planforms are proposed to also be sensitive to pre-existing structure (i.e. antecedence) or affected by stream capture/piracy (Anderson and Anderson 2010). For example, barbed drainage on the Colorado Plateau has been interpreted as an indication that the Colorado River once flowed towards the northeast (Lucchitta 1972). 

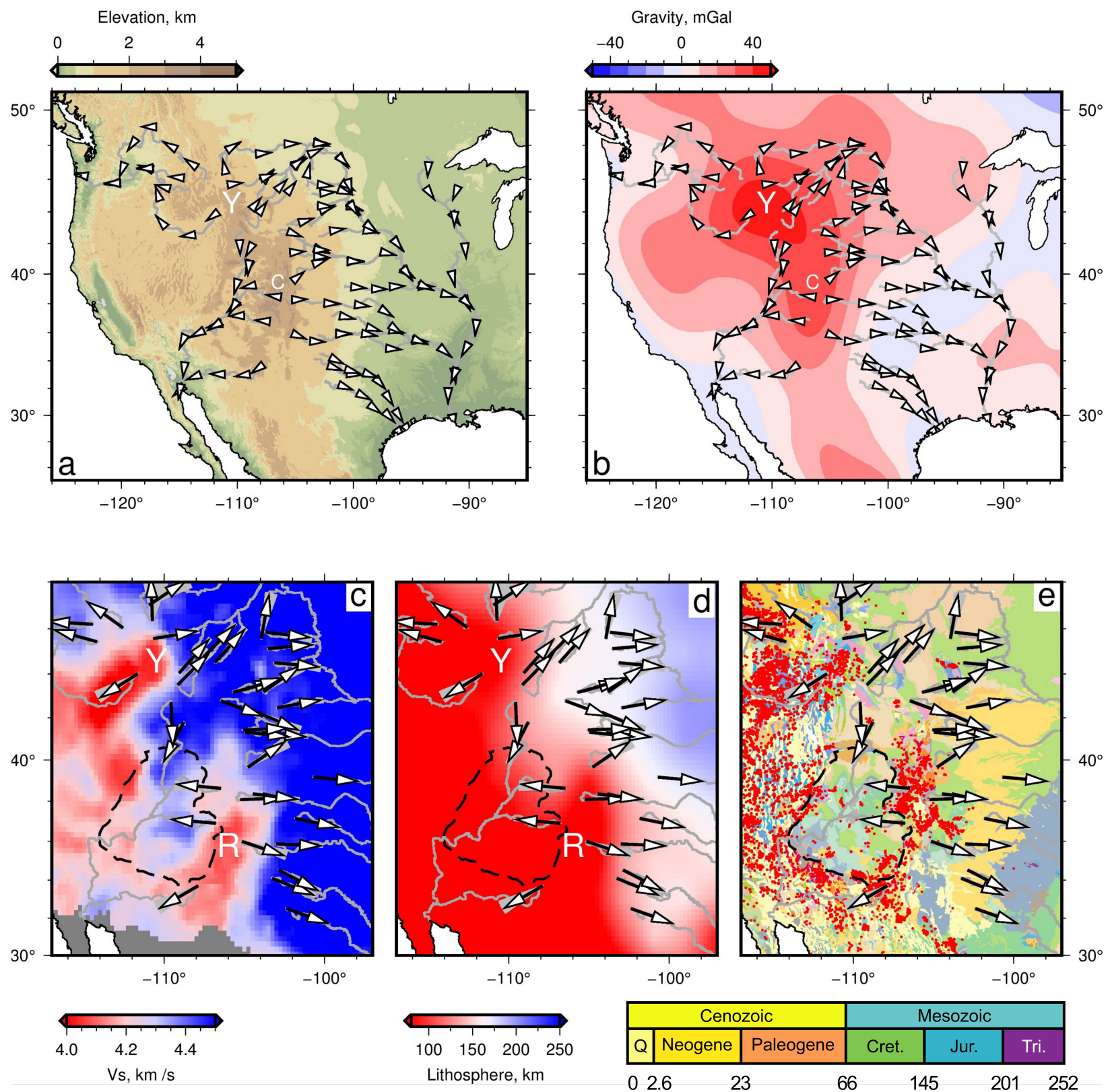

Figure 3: Planform deconvolution. (a) Flow directions (white vectors) overlain on major tributaries of the Colorado, Columbia and Mississippi rivers (gray curves). Vectors were generated from transformed river azimuths filtered to remove wavelengths $<$ $1000 \mathrm{~km}$ and are shown every $\sim 300 \mathrm{~km}$ for clarity, nearby parts of these rivers have similar azimuths. $\mathrm{Y}=\mathrm{Yellowstone}$; $\mathrm{C}=$ Colorado River shown in Figure 2. (b) Rivers and long wavelength azimuths atop long wavelength free-air gravity anomalies (Figure 1). Note rivers flow away from the crest of the western North American swell in a simple, broadly radial, pattern. (c) Average flow paths of the upper $500 \mathrm{~km}$ of rivers overlain on USA.2016 shear wave tomographic model at $75 \mathrm{~km}$ depth centered on western North America (Shen and Ritzwoller 2016). Black/gray vectors $=$ average/all long wavelength $(>1000 \mathrm{~km})$ azimuths for first $500 \mathrm{~km}$ of major rivers shown in panels (a) and (b); gray curves = river planforms. Dashed curve fringes Colorado Plateau. $\mathrm{Y} / \mathrm{R}=$ Yellowstone/Rio Grande rift. (d) Flow atop CAM2016 lithospheric thickness map, which was generated by converting shear wave velocities into temperature (Ho et al. 2016). (e) Flow atop Cenozoic magmatism (red circles) from NAVDAT inventory and surficial geology from the GMNA dataset (www .navdat.org; ngmdb.usgs.gov/gmna/). Legend shows lithologies coloured by age; numbers $=$ age in millions of years. 

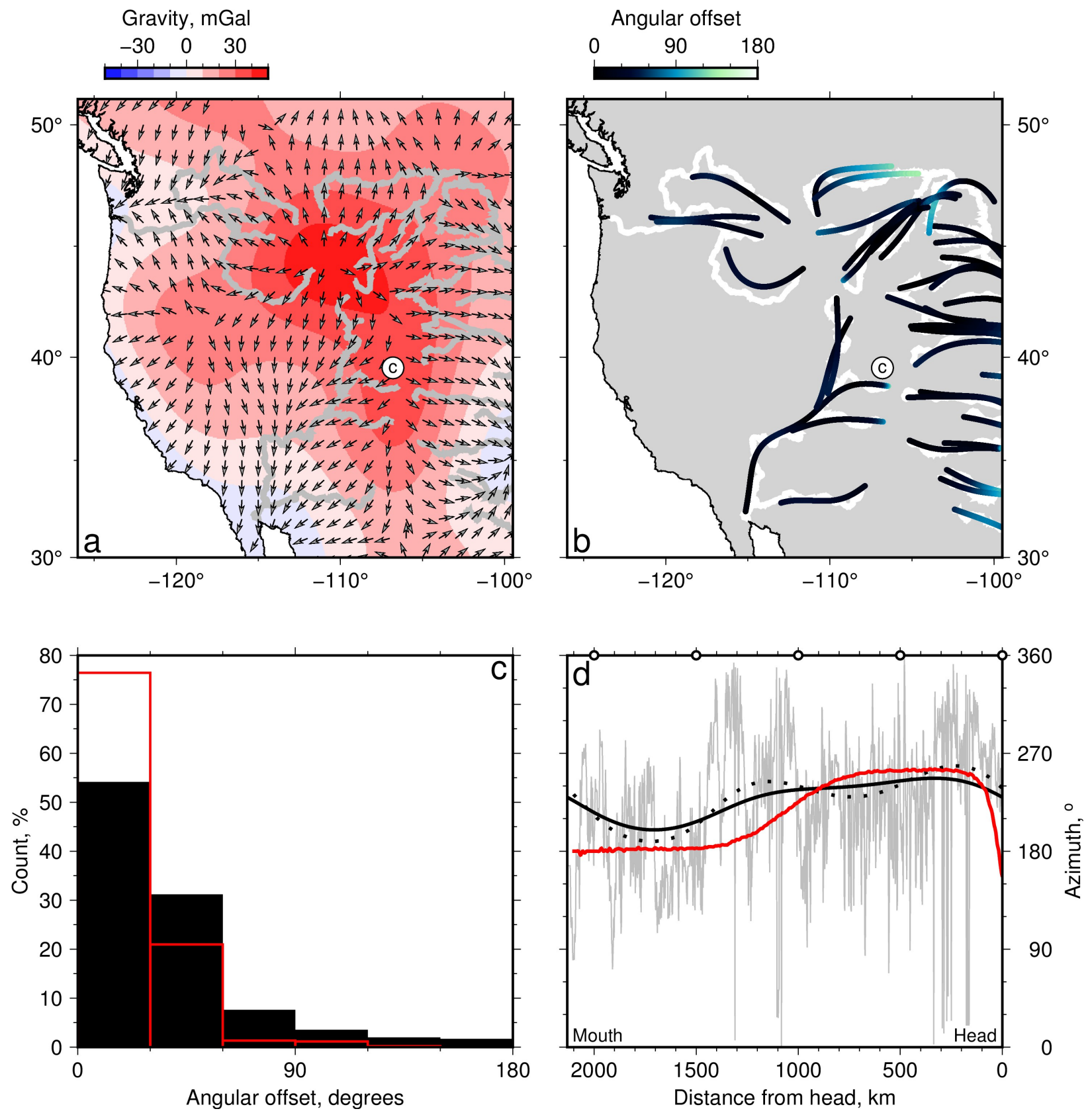

Figure 4: Comparison of observed long wavelength flow directions of the Colorado River and predicted sub-plate support. (a) Red-white-blue color scale = long wavelength free-air gravity anomalies $(\sim 800-2500 \mathrm{~km})$ from GRACE dataset, which are a rough guide to loci of sub-plate support (Tapley et al. 2005; Colli et al. 2016). Vectors = flow directions (gradients) calculated using gravity data, i.e. $g^{\prime}$ (see body text). (C)= Colorado River; gray curves $=$ full resolution drainage. $($ b) Colored curves $=$ positions of rivers calculated by forward geodetic transformation of long wavelength $(>1000 \mathrm{~km})$ component of azimuths; colors $=$ angular offset between azimuths of long wavelength components of actual river and $g^{\prime}$ (see body text). White curves $=$ full resolution drainage. (c) Histogram (binwidth $=30^{\circ}$ ) showing difference (angular offset) between azimuths calculated from gravity data $\left(g^{\prime}\right)$ and long wavelength flow paths: red $=$ Colorado River; black $=$ other rivers shown in panel $b$. (d) Flow direction (azimuths) of Colorado River: gray/dotted/black $=$ full resolution/ $>1000 \mathrm{~km}$ filter $/ 800-2500 \mathrm{~km}$ filter. Red $=$ predicted flow directions from long wavelength $(800-2500 \mathrm{~km})$ gravity. 

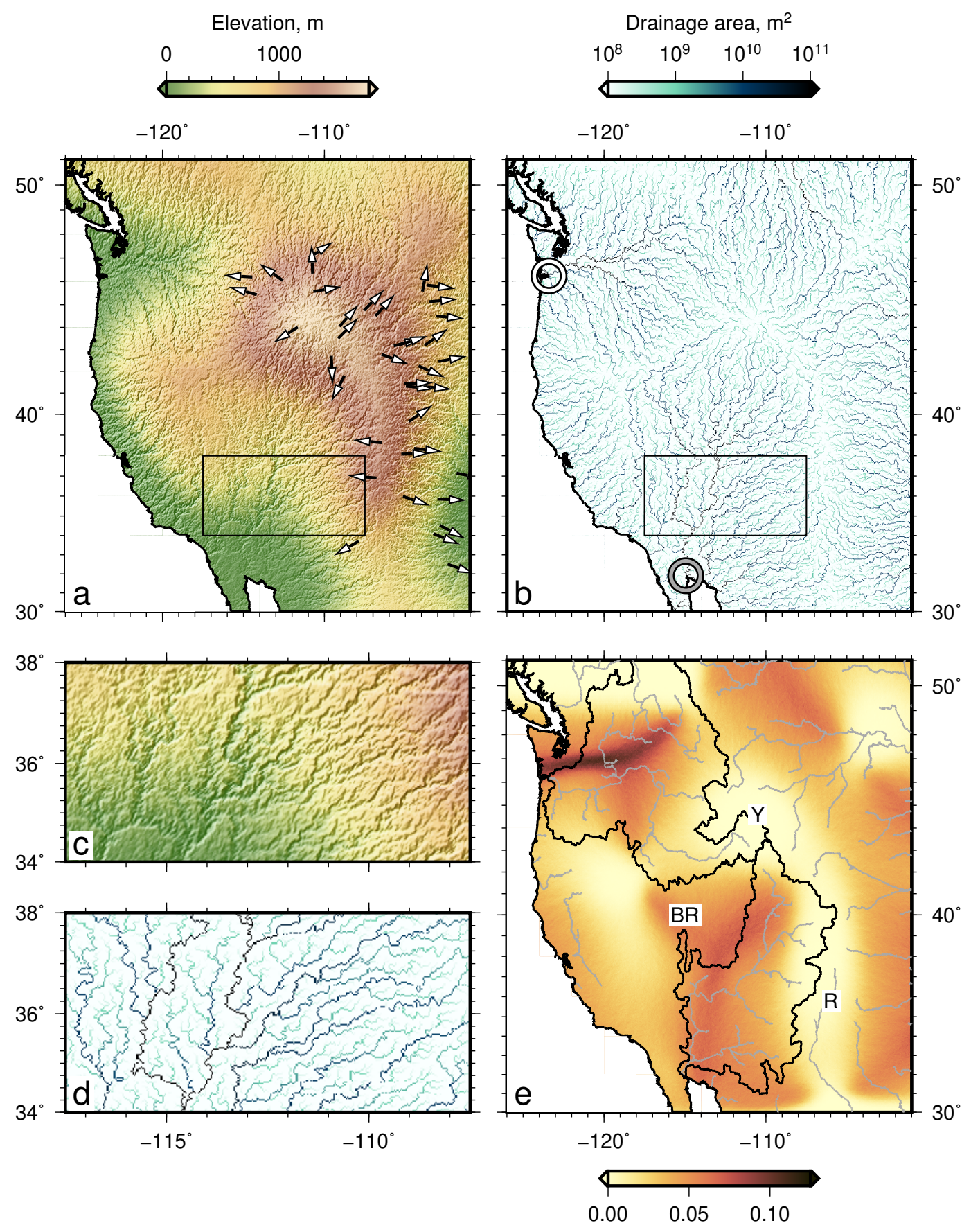

Probability of channel with area $>10^{10} \mathrm{~m}^{2}$

Figure 5: Synthetic and probabilistic drainage patterns. (a) Synthetic topography generated by solving the stream power erosional model using Landlab routines and an initial condition that includes calculated dynamic support and small amplitude (up to $\pm 100 \mathrm{~m}$ ) random uniform noise. Coastline is shown but not used in this landscape simulation. Note radial drainage pattern away from swell crest; vectors show long wavelength azimuths of upper $500 \mathrm{~km}$ of actual rivers (see Figure 3c). Box shows area in panel c. (b) Predicted upstream drainage area from panel a, which is highest in channels. Mouths of actual Columbia/Colorado Rivers are shown by white/gray circles. Note sinuous channels at small scale (panel d) and radial pattern at larger scales. (c-d) Close ups of boxes shown in panels a and b. (e) Probability of any model cell containing a channel with upstream area $>10^{10} \mathrm{~m}^{2}$ after 10,000 runs initiated with random noise. Gray lines indicate real location of channels of area $>10^{10} \mathrm{~m}^{2}$ from HydroSheds dataset, internal-drainage removed (www .hydrosheds .org.) Black lines indicate real catchment boundaries of Colorado and Columbia rivers. $\mathrm{BR}=\mathrm{Basin}$ and Range Province $\mathrm{Y}=$ Yellowstone; $\mathrm{R}=$ Rio Grande Rift. 
To explore whether sub-plate forcing can 'over-write' the effects of pre-existing structure we use landscape evolution models. A similar problem has been examined by parameterising landscape evolution models using uplift predicted from 'backwards in time' global convection models (Braun et al. 2013; Faccenna et al. 2019). Our approach has three steps. First, we generated an initial condition (a surface) that contains up to $100 \mathrm{~m}$ of uniformly distributed random noise. This surface can be modified to test the impact of different distributions of antecedent noise. Second, calculated dynamic topography was added to this surface by converting long wavelength free-air gravity anomalies using an admittance of $25 \mathrm{mGal} / \mathrm{km}$ (Figure $1 \mathrm{~b}$ ). We note that this surface is similar to cumulative post-Cretaceous uplift mapped using the distribution of marine rocks in western North America, and its crest coincides with loci of Cenozoic basaltic magmatism (Klocking et al. 2018; Fernandes et al. 2019). Simulations of North American landscape evolution parameterized in a similar way have yielded broadly stable Cenozoic drainage planforms (Fernandes et al. 2019). In the third step the resultant surface is eroded so that channels form using the well known stream power formulation of fluvial erosion, which has the form of a non-linear advective equation

$$
\frac{\partial z}{\partial t}=-v A^{m} \nabla z
$$

where $z$ is elevation, $t$ is time, and $A$ is upstream drainage area (Howard and Kerby 1983; Rosenbloom and Anderson 1994; Tinkler and Wohl 1998; Whipple and Tucker 1999). Erosional constants $v=0.99 \mathrm{~m}^{0.4} / \mathrm{Myr}$ and $m=0.4$ were calibrated for North America using incision measurements in the Grand Canyon (Fernandes et al. 2019). Topographic sinks were filled, then Equation 6 was solved numerically using the 'Fastscape' algorithm as implemented in the LandLab package (Braun and Willett 2013; Barnes et al. 2014; Hobley et al. 2017; Barnhart et al. 2020). Flow-routing was performed with the 'D8' algorithm to calculate upstream drainage area. In all of the tests we ran channels formed during the first time step (by $5 \mathrm{ka}$ ).

Figures 5a-b show calculated topography and drainage areas at $5 \mathrm{ka}$ extracted from one model. This simple model does not include the coastline, nor transcurrent, extensional or compressional plate motions or complex hydraulic or geomorphic processes (e.g. thresholds). Despite the simple formulation, the calculated positions of major rivers and their mouths are in similar locations to actual large rivers (e.g. Colorado, Columbia, Mississippi tributaries). On smaller scales there is significant short-wavelength complexity, imparted by the initial distribution of noise (Figure $5 \mathrm{c}-\mathrm{d}$ ). These results suggest that the longwavelength planform is controlled by sub-plate support, but short-wavelength complexity can be generated by other processes. The long wavelength flow directions of large western North American rivers are therefore likely to be no older than the ongoing mantle support. This result is consistent with geomorphic and provenance studies, which indicate that the present day planform of rivers draining western North America has been broadly stable during the last few tens of millions of years (Galloway et al. 2011; Blum and Pecha 2014; Fernandes et al. 2019).

Finally, to explore this result further, we ran 10,000 simulations where different distributions of uniform antecedent noise (with amplitudes up to $100 \mathrm{~m}$ ) were inserted into the starting condition. The locations of major channels (defined as a cell with upstream area $>10^{10} \mathrm{~m}^{2}$ ) were extracted from each of these runs. The probability of any cell containing a major channel was determined by dividing the total number of times a cell contained a channel by the total number of simulations. The resultant 'probabilistic drainage map' is shown in Figure 5e. This map indicates regions where channels occurred more frequently during the 10,000 simulations. As we saw with the single model run, despite the simplicity of these models, positions of predicted rivers with highest probabilities and their mouths overlap with the catchments of large rivers draining western North America (e.g. Colorado, Columbia). The least accurate predictions are found in the Rio Grande rift, Basin and Range and San Joaquim basin. This result is unsurprising given our model does not include strike-slip or extensional tectonics. Channel locations at small scales are more variable and depend on the distribution of inserted noise. We explored the impact of running the landscape evolution model for a longer time by inserting linearly increasing uplift from 20 to $0 \mathrm{Ma}$. The resultant planforms are very similar to those generated in our previous tests. Planforms at large scales thus appear to be deterministic and predictable and can emerge despite local complexity. We interpret these results as a strong indication that the planforms of large western North American rivers are controlled principally by the mantle. At smaller scales, $\mathrm{O}(1-10) \mathrm{km}$, planforms are moderated by other environmental variables (e.g. lithology, biota, hydrodynamics).

\section{Conclusions}

We have mapped the scale dependence of river networks so that they can be compared to independent observations at appropriate scales (e.g. of sub-plate support). A continuous wavelet approach was used to transform the complex form of distanceazimuth series into the distance-wavenumber domain. Results indicate that the flow-directions of western North American rivers (e.g. Colorado, Columbia, Mississippi) are principally controlled by the shape of long wavelength $\mathrm{O}\left(10^{2}-10^{3}\right) \mathrm{km}$ topography. The correlation between long wavelength gravity anomalies, sub-plate shear wave velocity anomalies, magmatism and river flow directions indicates the importance of sub-plate support in maintaining the flow direction of these rivers and the positions of their mouths. Generation of synthetic landscapes further demonstrates that large-scale planform structure of rivers is set by the solid earth and moderated by geomorphic and smaller scale processes. We suggest that comparing mapped spectral power of azimuthal series to other environmental variables could give insight into shape and origin of planforms at all scales.

\section{Code Availability}

Software to perform the directional wavelet analysis is provided at: github.com/alexlipp/directional-wavelets and archived at the point of submission at doi.org/10.5281/zenodo. 4067111. ASTER Topographic data can be accessed at from https://asterweb.jpl.nasa.gov/gdem.asp. Wavelet transforms were performed using a modified version of the python mply library (Albanese et al. 2012). 


\section{ACKNOWLEDGEMENTS}

We thank V. Fernandes, C. O'Malley, F. Richards, N. White and an anonymous reviewer for their constructive advice. AGL is funded by the Natural Environment Research Council Grantham Institute SSCP DTP (grant number NE/L002515/1). This work was supported by CASP and the Leverhulme Trust (grant number RPG-2019-073).

\section{REFERENCES}

Albanese, D., R. Visintainer, S. Merler, S. Riccadonna, G. Jurman, and C. Furlanello (2012). mlpy: Machine Learning Python. arXiv: 1202.6548 [cs].

Anderson, R. S. and S. P. Anderson (2010). Geomorphology: The Mechanics and Chemistry of Landscapes. 1st ed. Cambridge, UK: Cambridge University Press.

Atwater, T. (1970). "Implications of Plate Tectonics for the Cenozoic Tectonic Evolution of Western North America". Geological Society of America Bulletin 81, pp. 3513-3536.

Barnes, R., C. Lehman, and D. Mulla (2014). "Priority-flood: An optimal depression-filling and watershed-labeling algorithm for digital elevation models". Computers $\mathcal{E}$ Geosciences 62 , pp. 117-127. DoI: 10.1016/j. cageo.2013.04.024.

Barnhart, K. R., E. W. H. Hutton, G. E. Tucker, N. M. Gasparini, E. Istanbulluoglu, D. E. J. Hobley, N. J. Lyons, M. Mouchene, S. S. Nudurupati, J. M. Adams, and C. Bandaragoda (2020). "Short communication: Landlab v2.0: a software package for Earth surface dynamics". Earth Surface Dynamics 8.2, pp. 379-397. Dor: https : //doi .org/10.5194/esurf-8379-2020.

Black, B. A., J. T. Perron, D. Hemingway, E. Bailey, F. Nimmo, and H. Zebker (2017). "Global drainage patterns and the origins of topographic relief on Earth, Mars, and Titan”. Science 356.6339, pp. 727-731. DoI: 10.1126/science . aag0171.

Blum, M. and M. Pecha (2014). "Mid-Cretaceous to Paleocene North American drainage reorganization from detrital zircons". Geology 42.7, pp. 607-610. DoI: 10.1130/G35513.1.

Braun, J. (2010). "The many surface expressions of mantle dynamics". Nature Geoscience 3.12, pp. 825-833. Dor: 10 1038/ngeo1020.

Braun, J., X. Robert, and T. Simon-Labric (2013). "Eroding dynamic topography". Geophysical Research Letters 40.8, pp. 1494-1499. Dor: 10.1002/grl.50310.

Braun, J. and S. D. Willett (2013). "A very efficient O(n), implicit and parallel method to solve the stream power equation governing fluvial incision and landscape evolution". Geomorphology 180-181, pp. 170-179. Dor: 10.1016/j.geomorph . 2012.10.008.

Buehler, J. S. and P. M. Shearer (2017). "Uppermost mantle seismic velocity structure beneath USArray". Journal of Geophysical Research: Solid Earth 122.1, pp. 436-448. DoI: 10. 1002/2016 JB013265.

Colli, L., S. Ghelichkhanand, and H.-P. Bunge (2016). "On the ratio of dynamic topography and gravity anomalies in a dynamic Earth". Geophysical Research Letters 43, pp. 2510 2516. DOI: 10.1002/2016GL067929.

Cox, K. G. (1989). "The role of mantle plumes in the development of continental drainage patterns". Nature 342, pp. 873877.

Daubechies, I. (1990). "The wavelet transform, time-frequency localization and signal analysis". IEEE Transactions on Information Theory 36.5, pp. 961-1005. DoI: 10.1109/18.57199.
Donelan, M. A., W. M. Drennan, and A. K. Magnusson (1996). "Nonstationary Analysis of the Directional Properties of Propagating Waves". Journal of Physical Oceanography 26.9, pp. 1901-1914. DoI: 10 . 1175/1520-0485(1996) $026<1901$ : NAOTDP> $2.0 . \mathrm{CO} ; 2$.

Donelan, M. A., J. Hamilton, and W. H. Hui (1985). "Directional spectra of wind-generated ocean waves". Philosophical Transactions of the Royal Society of London. Series A, Mathematical and Physical Sciences 315, pp. 509-562. Dor: 10.1098/rsta.1985.0054.

Faccenna, C., P. Glisovic, A. Forte, T. W. Becker, E. Garzanti, A. Sembroni, and Z. Gvirtzman (2019). "Role of dynamic topography in sustaining the Nile River over 30 million years". Nature Geoscience. DoI: 10.1038/s41561-019-0472-x.

Farge, M. (1992). "Wavelet transforms and their applications to turbulence". Annual Review of Fluid Mechanics 24.1, pp. 395458. Dor: 10.1146/annurev.fl.24.010192.002143.

Fernandes, V. M., G. G. Roberts, N. White, and A. C. Whittaker (2019). "Continental-Scale Landscape Evolution: A History of North American Topography". Journal of Geophysical Research: Earth Surface 124. DoI: 10.1029/2018JF004979.

Galloway, W. E., T. L. Whiteaker, and P. Ganey-Curry (2011). "History of Cenozoic North American drainage basin evolution, sediment yield, and accumulation in the Gulf of Mexico basin". Geosphere 7.4, pp. 938-973. DoI: 10.1130 / GES00647.1.

Gerven, L. P. A. van and A. Hoitink (2010). "Analysis of river planform geometry with wavelets: Application to the Mahakam River reveals geographical zoning". In: River, Coastal and Estuarine Morphodynamics. RCEM 2009. Vol. 1. 2 vols. London: Taylor \& Francis, pp. 29-37.

Gutierrez, R. R. and J. D. Abad (2014). "On the analysis of the medium term planform dynamics of meandering rivers". Water Resources Research 50, pp. 3714-3733. DoI: 10.1002/ $2012 W R 013358$.

Ho, T., K. Priestley, and E. Debayle (2016). "A global horizontal shear velocity model of the upper mantle from multimode Love wave measurements". Geophysical Journal International 207.1, pp. 542-561. DoI: 10.1093/g j i/ggw292.

Hobley, D. E. J., J. M. Adams, S. S. Nudurupati, E. W. H. Hutton, N. M. Gasparini, E. Istanbulluoglu, and G. E. Tucker (2017). "Creative computing with Landlab: an open-source toolkit for building, coupling, and exploring two-dimensional numerical models of Earth-surface dynamics". Earth Surface Dynamics 5.1, pp. 21-46. DoI: 10.5194/esurf-5-21-2017.

Howard, A. D. and G. Kerby (1983). "Channel changes in badlands". GSA Bulletin 94.6, pp. 739-752. Dor: 10.1130/00167606 (1983) $94<739$ : CCIB>2 .0. CO; 2.

Klocking, M., N. J. White, J. Maclennan, D. McKenzie, and J. G. Fitton (2018). "Quantitative Relationships Between Basalt Geochemistry, Shear Wave Velocity, and Asthenospheric Temperature Beneath Western North America". Geochemistry, Geophysics, Geosystems 19.9, pp. 3376-3404. DoI: 10.1029/ $2018 \mathrm{GC007559.}$

Kumar, P. and E. Foufoula-Georgiou (1997). "Wavelet analysis for geophysical applications". Reviews of Geophysics 35.4, pp. 385-412. DoI: 10.1029/97RG00427.

Lucchitta, I. (1972). "Early History of the Colorado River in the Basin and Range Province". GSA Bulletin 83, pp. 1933-1948. DOI: 10 . 1130/0016 - 7606 (1972) 83 [1933: EHOTCR] 2 . 0 . $\mathrm{CO} ; 2$. 
McKenzie, D. (2010). “The influence of dynamically supported topography on estimates of Te". Earth and Planetary Science Letters 295, pp. 127-138.

Rinaldo, A., I. Rodriguez-Iturbe, R. Rigon, E. Ijjasz-Vasquez, and R. L. Bras (1993). "Self-organized fractal river networks". Phys. Rev. Lett. 70 (6), pp. 822-825. Dor: 10.1103/ PhysRevLett.70.822.

Roberts, G. G. (2019). "Scales of Similarity and Disparity Between Drainage Networks". Geophysical Research Letters 46.7, pp. 3781-3790. DoI: 10.1029/2019GL082446.

Roberts, G. G., N. J. White, G. L. Martin-Brandis, and A. G. Crosby (2012). "An uplift history of the Colorado Plateau and its surroundings from inverse modeling of longitudinal river profiles". Tectonics 31.4. DoI: 10.1029/2012TC003107.

Roberts, G. G., N. White, and B. H. Lodhia (2019). "The generation and scaling of longitudinal river profiles". Journal of Geophysical Research: Earth Surface 124, pp. 137-153. DoI: 10.1029/2018JF004796.

Rosenbloom, N. A. and R. S. Anderson (1994). "Hillslope and channel evolution in a marine terraced landscape, Santa Cruz, California”. Journal of Geophysical Research: Solid Earth 99.B7, pp. 14013-14029. DoI: 10.1029/94JB00048.

Rudge, J. F., G. G. Roberts, N. J. White, and C. N. Richardson (2015). "Uplift histories of Africa and Australia from linear inverse modeling of drainage inventories". Journal of Geophysical Research. Earth Surface 120, pp. 894-914. DoI: 10.1002/2014 JF003297.

Scheingross, J. S., A. B. Limaye, S. W. McCoy, and A. C. Whittaker (2020). "The shaping of erosional landscapes by internal dynamics". Nature Reviews Earth E Environment, pp. 1-16. DoI: $10.1038 /$ s43017-020-0096-0.

Shen, W. and M. H. Ritzwoller (2016). "Crustal and uppermost mantle structure beneath the United States". Journal of Geophysical Research: Solid Earth 121.6, pp. 4306-4342. DoI: 10.1002/2016 JB012887.

Shugar, D. H., J. J. Clague, J. L. Best, C. Schoof, M. J. Willis, L. Copland, and R. G. H. (2017). "River piracy and drainage basin reorganization led by climate-driven glacier retreat". Nature Geoscience 10.5, pp. 370-375. Dor: 10.1038/ ngeo2932.

Stephenson, S. N., G. G. Roberts, M. J. Hoggard, and A. C. Whittaker (2014). "A Cenozoic uplift history of Mexico and its surroundings from longitudinal river profiles". Geochemistry, Geophysics, Geosystems 15, pp. 4734-4758. DOI: 10 . 1002/2014GC005425.

Tapley, B., J. Ries, S. Bettadpur, D. Chambers, M. Cheng, F. Condi, B. Gunter, Z. Kang, P. Nagel, R. Pastor, T. Pekker, S. Poole, and F. Wang (2005). "GGM02 — An improved Earth gravity field model from GRACE”. J. Geodesy 79.467. Dor: 10.1007/s00190-005-0480-z.

Tinkler, K. J. and E. E. Wohl (1998). Rivers Over Rock: Fluvial Process in Bedrock Channels. Washington, DC, USA: American Geophysical Union, Geophysical Monograph 107.

Torrence, C. and G. P. Compo (1998). "A Practical Guide to Wavelet Analysis". Bulletin of the American Meteorological Society 79, pp. 61-78.

Wernicke, B. (1985). "Uniform-sense normal simple shear of the continental lithosphere". Canadian Journal of Earth Sciences 22.1, pp. 108-125. DoI: 10.1139/e85-009.

Wessel, P., S. W. H. F., R. Scharroo, J. Luis, and F. Wobbe (2013). "Generic Mapping Tools: Improved Version Released". Eos,
Transactions American Geophysical Union 94, pp. 409-410. DoI: 10.1002/2013E0450001.

Whipple, K. X. and G. E. Tucker (1999). "Dynamics of the stream-power river incision model: Implications for height limits of mountain ranges, landscape response timescales, and research needs". Journal of Geophysical Research: Solid Earth 104.B8, pp. 17661-17674. DoI: 10 . 1029 / 1999JB900120. 


\section{SUPPORTING INFORMATION}

\section{Alternative directional wavelet transform}

In the main manuscript we describe a methodology to transform directional time series using complex numbers. An alternative intuitive approach is to transform real-valued eastings and northings generated from azimuthal time series. Eastings and northings are calculated such that

$$
e(x)=\sin (\pi \theta(x) / 180), \quad n(x)=\cos (\pi \theta(x) / 180),
$$

where $e(x)$ and $n(x)$ vary between -1 and $1, \theta$ is in degrees. The easting and northing distance-amplitude series are then independently transformed into the distance-wavenumber domain. The series were normalised to zero mean, e.g. $e^{\prime}(x)=e(x)-\bar{e}$, prior to transformation These real valued series are converted using a continuous wavelet transformation and real valued mother wavelets. The two series, $e^{\prime}(x)$ or $n^{\prime}(x)$, are transformed such that,

$$
W_{x}^{e}(s)=\sum_{x^{\prime}=0}^{N-1} e_{x}^{\prime} \psi\left[\frac{x^{\prime}-x}{s}\right], \quad \text { and } \quad W_{x}^{n}(s)=\sum_{x^{\prime}=0}^{N-1} n_{x}^{\prime} \psi\left[\frac{x^{\prime}-x}{s}\right]
$$

where $W_{x}^{e}(s)$ and $W_{x}^{n}(s)$ are the transformed versions of the easting and northing series as a function of scale, $s$. The easting and northing distance-amplitude series can be reconstructed by summing their respective wavelet transforms across scales (i.e. the inverse transformation). Following Torrence and Compo's notation,

$$
e_{x}=\frac{\delta_{j} \delta t^{1 / 2}}{1.7379} \sum_{j=0}^{J} \frac{W_{x}^{e}\left(s_{j}\right)}{s_{j}^{1 / 2}}, \quad \text { and } \quad n_{x}=\frac{\delta_{j} \delta t^{1 / 2}}{1.7379} \sum_{j=0}^{J} \frac{W_{x}^{n}\left(s_{j}\right)}{s_{j}^{1 / 2}}
$$

for the DOG mother wavelet used in this study Torrence and Compo 1998. At this stage the means (e.g. $\bar{e}$ and $\bar{n}$ ) are added to the reconstructed series. The azimuth series as a function of distance can then be constructed using

$$
\theta_{x}=\frac{180}{\pi} \arctan 2\left(e_{x}+\bar{e}, n_{x}+\bar{n}\right)
$$

Filtering of the azimuth series is performed by solving Equation 9 between scales of interest and calculating $\theta_{x}$ using filtered eastings and northings (Equation 10).

\section{SuPPORTING FiguRES}

Figure S1 shows the results of transforming the azimuths of the Colorado river using the complex and easting-northing time series. Figure $\mathrm{S} 1$ shows the inverse wavelet transform of the complete dataset. The distance-azimuth time series are a high fidelity representation of the flow directions of the Colorado river. This figure also shows that transforming the complex or easting-northing time series give the same results, as expected.

Figure S2 shows the average flow directions of the long wavelength $(>1000 \mathrm{~km}$ ) components of the upper $500 \mathrm{~km}$ of rivers draining western North America. These results are discussed in the body text of the main manuscript. 

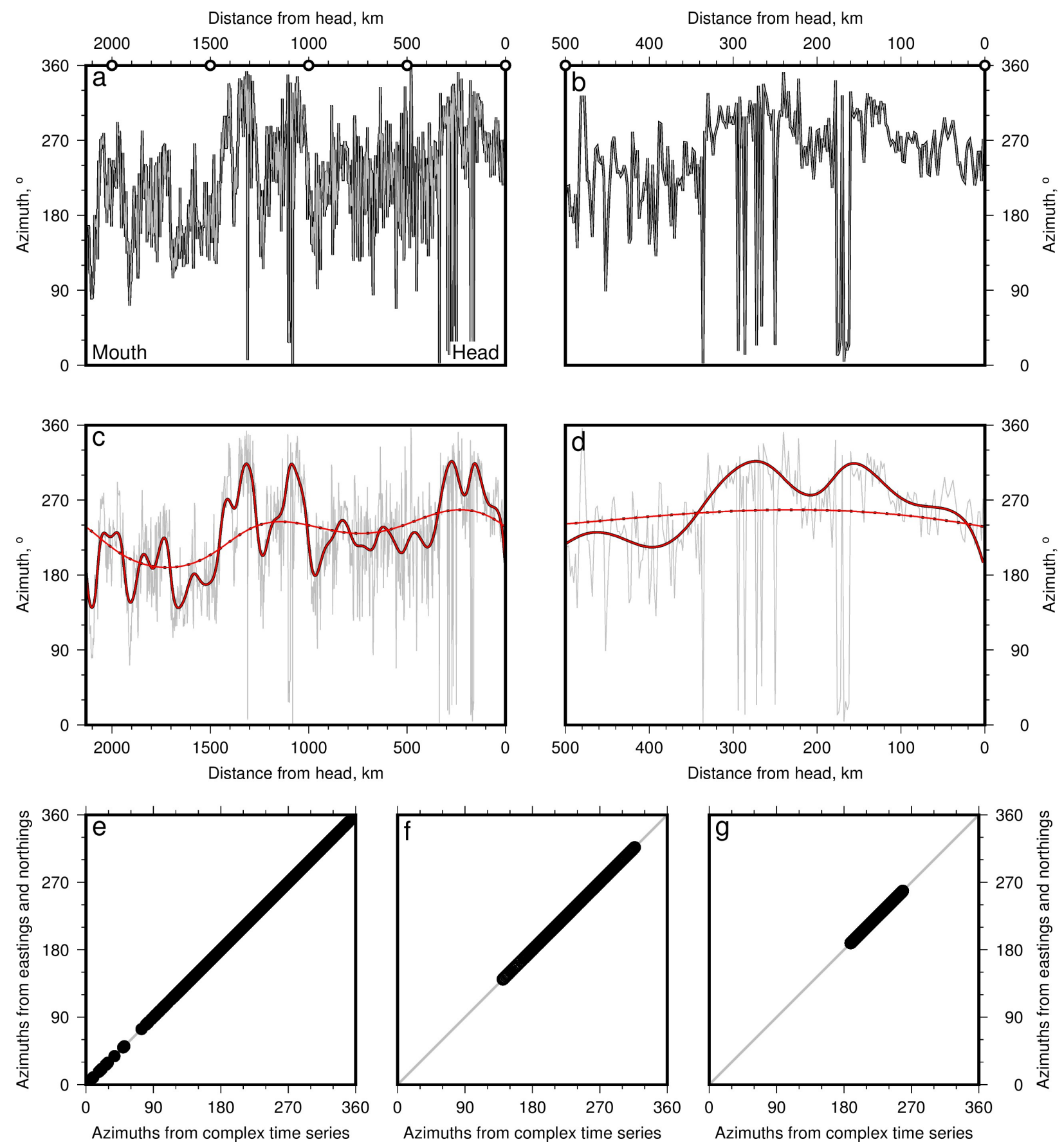

Supplementary Figure 1: Wavelet transform of Colorado river flow directions. (a) Black curve $=$ azimuths of full resolution data set $(\delta x=2 \mathrm{~km})$. Gray $=$ results from inverse wavelet transform. Circles atop panel are locations along Colorado river shown in Figure 2c of main manuscript. Panel (b) shows first $500 \mathrm{~km}$ in more detail. (c-d) Gray $=$ full resolution azimuths. Black dotted and dash curves $=$ azimuths filtered to remove wavelengths less than $100 \mathrm{~km}$ and $1000 \mathrm{~km}$ using complex time series. Red curves $=$ results from transforming easting and northing time series. (e-g) Azimuths calculated from the complex time series compared to those generated from easting and northing time series for full resolution, $\lambda>100 \mathrm{~km}$, and $\lambda>1000 \mathrm{~km}$, respectively. Gray line $=$ 1:1 relationship. 

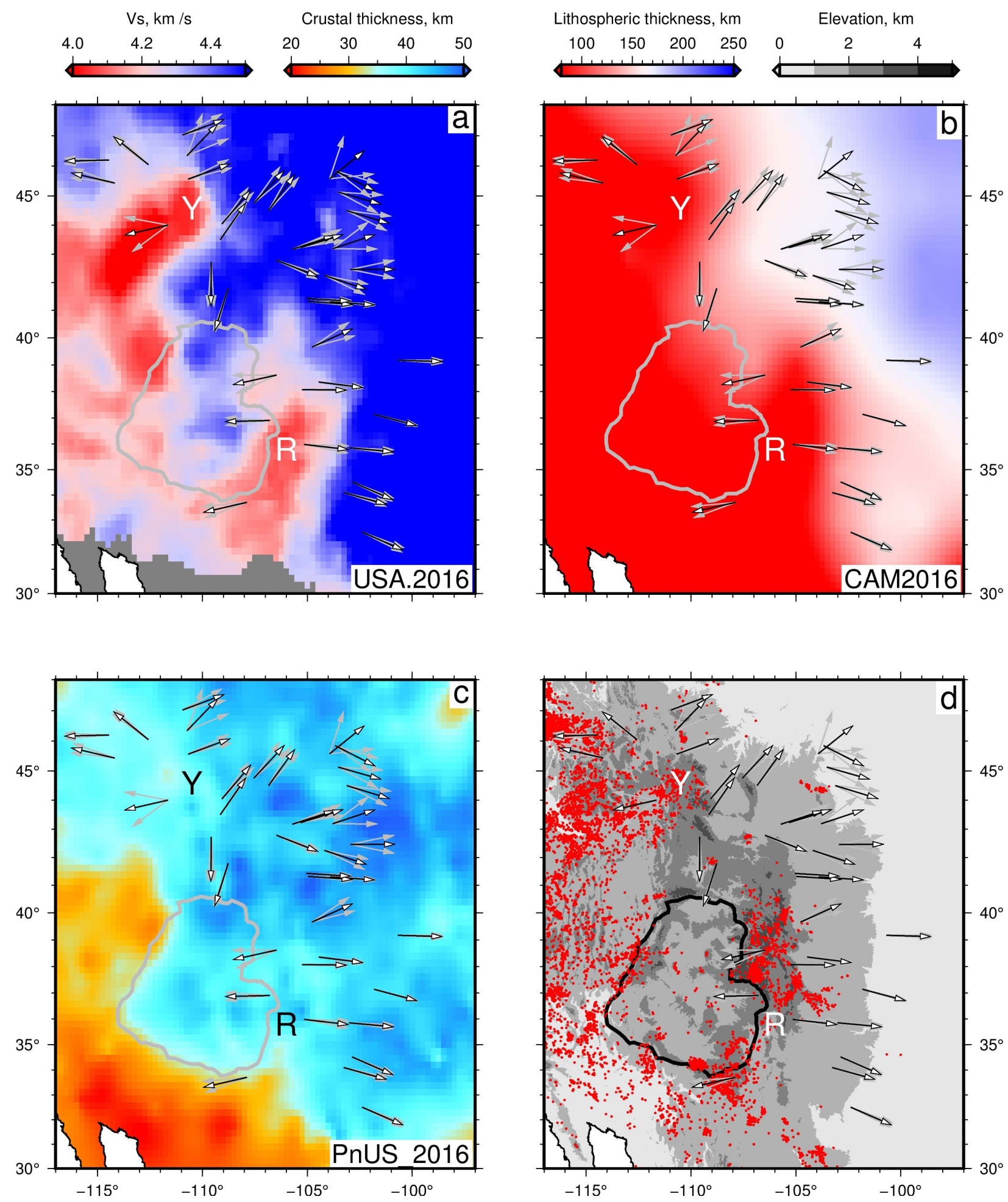

Supplementary Figure 2: Long wavelength flow directions compared to independent observations. (a) $75 \mathrm{~km}$ depth slice through USA.2016 shear wave tomographic model Shen and Ritzwoller 2016. Gray polygon = fringe of Colorado Plateau. Y/R $=$ Yellowstone $/$ Rio Grande rift. Black vectors $=$ average flow directions of upper $500 \mathrm{~km}$ of the long wavelength $(>1000 \mathrm{~km})$ components of large western North American rivers. Gray vectors = extrema. (b) Calculated lithospheric thickness from CAM2016 model Ho et al. 2016. (c) Crustal thickness from PnUS_2016 model Buehler and Shearer 2017. (d) Elevations (ETOPO1) and Cenozoic magamatism (red circles) from NAVDAT database. 